\title{
HUBUNGAN ANTARA KEPERCAYAAN DIRI DAN REGULASI EMOSI TERHADAP KECEMASAN MENGHADAPI PERTANDINGAN PADA ATLET KARATE DI KOTA DEMAK
}

\author{
Syahida Alwin Widya Putri dan Agustin Handayani \\ Fakultas Psikologi, Universitas Islam Sultan Agung Semarang, Jl. Kaligawe Raya km 4, Semarang \\ Email: agustinhandayani75@gmail.com
}

\begin{abstract}
Abstrak
Penelitian ini bertujuan mengetahui hubungan antara kepercayaan diri dan regulasi emosi terhadap kecemasan menghadapi pertandingan pada atlet karate di kota Demak. Populasi penelitian ini adalah 74 atlet. Teknik sampling yang digunakan adalah studi populasi. Pengambilan data menggunakan tiga skala yaitu kecemasan menghadapi pertandingan, kepercayaan diri dan regulasi emosi. Skala kecemasan menghadapi pertandingan terdiri dari 29 aitem dengan uji daya beda berkisar 0,267-0,761 dan reliabilitas sebesar 0,874. Skala kepercayaan diri terdiri dari 45 aitem dengan uji daya beda aitem berkiasar 0,293-0,688 dan reliabilitas sebesar 0,919. Skala regulasi emosi terdiri dari 11 aitem dengan uji daya beda berkisar 0,296-0,467. Subjek penelitian adalah atlet karate di Demak. Analisis data menggunakan regresi dua prediktor dan korelasi bivariate. Hasil penelitian menunjukkan bahwa ada hubungan yang sangat signifikan antara kepercayaan diri dan regulasi emosi terhadap kecemasan menghadapi pertandingan, $R 12 y=0,629$, $F_{\text {hitung }}=23,269, p=0,000(p<0,01)$. Selanjutnya ada hubungan negatif yang sangat signifikan antara kepercayaan diri terhadap kecemasan menghadapi pertandingan, $\mathrm{rx}_{1} \mathrm{y}=-$ $0,616, p=0,000(p<0,01)$ dan ada hubungan negatif yang signifikan antara regulasi emosi terhadap kecemasan menghadapi pertandingan, $r_{x 2 y}=-0,420, p=0,000(p<0,01)$. Kepercayaan diri dan regulasi emosi memberikan kontribusi sebesar $39,6 \%$ sedangkan $60,4 \%$ dipengaruhi faktor lain.
\end{abstract}

Kata kunci : Kecemasan menghadapi pertandingan, Kepercayaan diri dan Regulasi emosi

\section{RELATIONSHIP BETWEEN SELF-CONFIDENCE AND EMOTIONAL REGULATION ON ANXIETY AMONG KARATE ATHLETES IN THE CITY OF DEMAK}

\begin{abstract}
This study aims to determine the relationship between self-confidence and emotional regulation of anxiety to face the game at karate athletes in the city of Demak. The population of this study was 74 athletes. The sampling technique used is population study. Taking data using three scales of anxiety in the game, confidence and emotional regulation. The anxiety-facing scale consists of 29 items with different power test ranging from 0.267 to 0.761 and reliability of 0.874 . The self-confidence scale consists of 45 items with different aitem power test 0,293-0,688 and reliability 0,919. The emotional regulation scale consists of 11 items with different power test ranging from 0.296 to 0.467. Research subjects were karate athletes in Demak. Data analysis used regression of two predictors and bivariate correlation. The results showed that there was a very significant relationship between self-confidence and emotional regulation of anxiety against the match, $R 12 y=0.629$, Fcount $=23.269$, $p=0,000$ ( $p$ <.01). Furthermore there is a very significant negative relationship between confidence in anxiety against the match, $r x_{1} y=-0.616, p=0,00(p<0.01)$ and there is a significant negative relationship between emotional regulation of anxiety against the match, $r x_{2} y=-0.420, p=0,000(p<0.01)$. Confidence and emotional regulation contributed $39.6 \%$ while $60.4 \%$ was influenced by other factors.
\end{abstract}

Keywords: Anxiety of the game, confidence, emotional regulation 


\section{Pendahuluan}

Perkembangan olahraga saat ini sangat bagus dimana ada dukungan pemerintah dalam mengembangkan prestasi olahraga. Pada membukaan Kejuaraan Dunia Karate Premier League 2014, Sekretaris Kemenko Kesra (Sesmenko Kesra) Drs. Sugihartatmo, menyampaikan pesan dari Menko Kesra yang berkata, "Prestasi olahraga suatu negara menjadi tolak ukur kemajuan bangsa dan negara, oleh karena itu persaingan mencapai pretasi olahraga antar Negara terus berjalan dengan berbagai pengembangan teknik dan teknologi bidang olahraga" (Humas, 2014). Berdasarkan pernyataan Menko Kesra, bahwa kemenangan dalam pertandingan sesuatu hal yang diharapkan para atlet.

Persaingan antar atlet dalam suatu pertandingan yang akan memunculkan prestasi. Seorang atlet wajib memperhatikan fakor psikisnya, mulai dari persiapan kondisi dan mental (Gunarsa, 2008).

Olahraga karate ialah salah satu cabang yang beregu maupun individu, namun lebih seringnya diadakan pertandingan perorangan. Adanya pertandingan karate perorangan membuat munculnya perasaan cemas yang dialami oleh para atlet. Sehingga kecemasan akan timbul secara alami (Rachmawati, Kartini, \& Priyatama, 2013).

Kecemasan adalah perasaan ketakutan dan kehawatiran terhadap yang akan dialami kedepannya, tanpa sebab khusus. Kecemasan akan terjadi apabila muncul perasaan-perasaan takut yang dipengaruhi seperti berkeringat, detak jantung yang berdetak kencang, tangan mulai dingin dan berkeringat, terasa pusing, kaki dan tangan terasa kesemutan, seringnya buang air kecil bahwakan sakit perut sampai diare, dan nafas terenggah-enggah. Hal tersebut termasuk gangguan psikis yang akan dialami oleh individu saat mengalami kecemasan, stress dan depresi (Rahmaiah, 2003).

Sebagai atlet hampir sebagian besar permasalahannya ialah muncul rasa cemas dan ini terjadi pada setiap cabang-cabang olahraga. Salah satu cabang yang sering mengalami kondisi tersebut adalah cabang olahraga karate. Karate adalah olahraga yang membutuhkan fisik dan mental yang kuat. Cabang olahraga karate menjadi cabang olahraga yang membutuhkan mental kuat dan kekuatan fisik yang tangguh, ini dikarenakan materi latihannya yang sangat berat, susah dan sulit. Hal ini dibutuhkan mental-mental yang tangguh dan ini terjadi karena porsi latihannya yang keras, melatih kepekaan insting dan stategi yang tepat (Prihastono, 1994).

Arti kata karate yaitu, pukulan kosong, dimana tidak memerlukan senjata ketika menghadapi kondisi darurat. Pada cabang olahraga lain akan ada hal-hal yang sama dihadapi seperti kecemasan, namun berbeda dalam hal materi latihannya dan tekan-tekanan yang diterima. Perbedaan porsi latihan akan sangat jelas terlihat antara olahraga beladiri dengan olahraga umum seperti volly, basket dan lain-lain (Sujoto, 1996).

Atlet sangatlah erat dengan berbagai permasalahan seperti kepercayaan diri, regulasi emosi dan kecemasan menghadapi pertandingan. Semua itu dapat terjadi pada beberapa atlet di cabang olahraga, salah satunya dialami oleh atlet karate. Sebagai atlet karate haruslah memiliki fisik dan mental kuat. Adanya kecemasan menghadapi pertandingan tidak menguntungkan bagi diri atlet.

Gunarsa (2008) memberikan komentar bahwa atlet dapat menilai situasi dan kondisi saat akan tanding dimana itu jauh-jauh hari sebelum tanding bahkan menjelang pertandingan menyebabkan reaksi bermacam-macam. Hal tersebut tergantung persepsi atlet dalam menyikapi pertandingan yang terdiri cara menanggapi suasana dan arena tanding sebagai ancaman, sehingga sebagai atlet akan muncul ketengangan dan perasaan cemas.

Menjelang pertandingan setiap atlet karate dituntut memiliki kepercayaan diri, ini diharapkan agar atlet mampu stabil dalam bertanding. Berbeda jadinya bila kepercayaan diri hilang atau kurang maka, 
akan berakibat fatal. Fatal yang akan terjadi dimana atlet tidak dapat fokus dan tidak mampu menangani hal-hal rumit akhirnya mengalami kekalahan (Cashmore, 2008).

Matsuda dalam berprestasi atlet diperlukannya mental yang siap, ini diharapkan agar dapat menyikapi ketegangannya baik saat latihan bahkan saat tanding (Santoso, 2005). Selain itu bila kepercayaan diri saja tidak diimbangi dengan adanya regulasi emosi maka, dampak kepercayaan diri dan kecemasan menghadapi pertandingan menjadi semakin mengkhawatirkan untuk para atlet. Perlunya regulasi emosi pada atlet, agar dapat mengontrol emosi dalam pertandingan nantinya. Suasana ketika di arena akan memanas membuat atlet harus mampu meregulasi emosinya. Kondisi emosi yang biasa dialami atlet ketika menghadapi pertandingan ialah perasaan cemas. Perasaan cemas menghadapi pertandingan akan sangat mempengaruhi performa atlet, maka meregulasi emosi sangat dibutuhkan (Amir, 2012).

Gross (2007) mengatakan bahwa regulasi emosi adalah cara mencari jalan keluar dimana itu dalam keadaan sadar maupun tidak sadar yang merujuknya agar bisa bertahan, menjadi kuat, dan dapat mengatur respon emosinya seperti berperilaku dan pengalaman-pengalaman emosi. Ini akan berpengaruh pada kepercayaan diri atlet juga berakibat munculnya kecemasan mengahadapi pertandingan.

\section{Landasan Teori}

Kecemasan menghadapi pertandingan menurut Tawakkal dan Hartati (2014) adalah suatu kondisi stress yang dialami akibat emosi negatif semakin tinggi serta cara interpretasi dirinya dan menilai keadaan di arena pertandingan. Satiadarma (2000) mengungkapkan bahwa kecemasan menghadapi pertandingan terjadi akibat pola berfikir negatif atas pertandingan yang akan terjadi, contohnya atlet memandang lawan lebih unggul, tampilnya jelek dan gagal menjadi juara atau kalah. Menurut Anshel (Cashmore, 2008) kecemasan dalam kompetisi ialah cerminan perasaan atlet tentang keberhasilan atau tidak berhasil, dimana kekalahan dapat terjadi.

Kecemasan menghadapi pertandingan bagi Sulistyo (2014) ialah suatu reaksi temperamental negatif seorang atlet saat menilai suasana pertandingan dimana itu terjadi adanya perasaan khawatir, hilangnya kendali, perasaan waspada yang menjadikan atlet-atlet tidak mampu dan lebih cepat lelah. Terjadinya ini akibat kondisi situasi yang tidak membuatnya nyaman dan keadaan waspada selalu untuk mendapatkan target yaitu sang juara atau pemenang.

Menurut Kroll (Ravaie \& Kumoluhadi, 2006) aspek-aspek kecemasan menghadapi pertandingan terdiri dari keluhan somatik, takut akan kegagalan, perasaan tidak mampu, hilangnya kontrol dan merasa bersalah. Keluhan somatic merupakan adanya situasi diri akibat stress dengan aktifitas fisiologis yang tinggi, contohnya seperti cemas menghadapi pertandingan dan efeknya, sebagai contoh buang air kecil, perut mulas, gemetar, tangan berkeringat. Takut akan kegagalan biasanya termanifestasi sebagai perasaan cemas dan pesimis atlet karena mempersepsikan gagal saat bertanding. Perasaan tidak mampu yakni perasaan bimbang atau ragu seorang atlet ketika akan bertanding dipenuhi rasa bersalah pada dirinya, akibat tidak mampu. Hilangnya kontrol biasanya berbentuk sikap diri yang tiba-tiba seolah-olah dikontrol adanya faktor eksternal, dimana tidak sedang mengatur segala hal yang sedang terjadi saat itu, contohnya beruntung. Hal ini akibat persepsi atlet yang tidak yakin terhadap kemampuannya. Terakhir, perasaan bersalah karena kesalahan diri yang dilakukan adanya kesalahan sia-sia ataupun akibat dipaksa melakukan kesalahan. Semua itu terjadi wajar dalam pertandingan. 
Kepercayaan diri merupakan modal awal pada setiap individu untuk terpenuhinya kebutuhankebutuhan dirinya (Hapsari \& Primastuti, 2014). Menurut Saranson (Komarudin, 2016) kepercayaan diri ialah perasaan dimana rasa itu berisi kemampuan, kekuatan dan kreatifitas dalam menerima tugas dan menciptakan motivasi untuk yakin bisa. Singer (1993) menjelaskan seorang atlet yang mempunyai kepercayaan diri ialah akan yakin dan berkompeten ketika melakukan sesuatu hal yang mau dihadapinya.

Fatchurahman \& Pratikto (2012) berpendapat bahwa kepercayaan diri adalah suatu sikap yang dimiliki atlet atas keyakinan, kemampuan dan cara pandang yang positif pada dirinya sendiri tanpa membanding-bandingkan dengan pihak lain. Sedangkan, Hakim (2005) menyatakan bahwa rasa percaya diri adalah keyakinan-keyakinan individu terdahap semua kelebihan yang ia miliki dan rasa yakin tersebut membuat diri mampu untuk menggapai segala keinginan dan tujuan di hidupnya.Bandura (2005) menjelaskan tentang kepercayaan diri merupakan sesuatu hal perasaan yang terdiri adanya kemampuan, kekuatan dan kreatifitas dalam memperoleh hasil yang disertai dari dalam seperti keyakinan akan pencapaian diri optimal.

Regulasi emosi yaitu suatu keharusan individu dapat mengontol diri, menilai, menelaah, motivasi dan mempertanggung jawabkan tindakannya (Bandura, 2005). Bonanno dan Mayne (2001) mengatakan bahwa regulasi emosi merupakan kemampuan individu yang dimiliki setiap orang dalam menilai pengalaman-pengalaman emosinya, mampu mengontrol, mengekspresikan emosi-emosi dan perasaan-perasaannya dalam kehidupan kesehariannya. Syahadat (2013) berpendapat bahwa yang dingatakan regulasi emosi ialah suatu solusi yang diharapkan untuk membantu dalam memfasilitasi kebutuhan-kebutuhan emosional pada diri. Selain itu regulasi emosi dapat dijabarkan sebagai keahlian individu agar sadar diri, mengatur pikirannya dan tindakannya ketika menghadapi emosi yang beda, seperti emosi positif atau emosi negatif.

Eisenberg dkk (2000) berpendapat bahwa regulasi emosi merupakan pencapaian dimana usaha untuk mengatur perhatian-perhatian yang terdiri dari merubah masalah, berfokuskan perhatian dan sadar akan kondisi pada emosi dengan tetap berusaha positive thinking melalui tahap neuropsikologis. Singkatnya regulasi emosi yaitu suatu tahap permulaan, perawatan, role model, intensitas diri dan tahap emosi yang dihubungkan dengan keadaan fisik saat itu, untuk tercapainya target.

\section{Metodologi Penelitian}

Populasi yang digunakan dalam penelitian ada 74 orang. Metode pengumpulan data dengan menggunakan alat ukur berupa skala psikologi. Ada tiga skala yang digunakan yaitu skala kecemasan menghadapi pertandingan dari Kroll (Ravaie \& Kumoluhadi, 2006) antara lain, perasaan tidak mampu, hilangnya kontrol, adanya keluhan somatik, takut gagal,dan rasa bersalah, skala kepercayaan diri dari Thomas dkk (2011) antara lain, multidimensial, malleable, durable, developed, protective, strong set of beliefs dan skala regulasi emosi dari Gross \& Jhon (2003) seperti penilaian emosi, pengaturan emosi dan pengungkapan emosi. Teknik sampling yang digunakan yaitu studi populasi dari Arikunto (2006).

\section{Hasil dan Pembahasan}

Perhitungan analisis dalam penelitian ini menggunakan bantuan SPSS versi 16.0. Pada penelitian didapatkan uji normalitas terdapat pada data kecemasan menghadapi pertandingan diperoleh nilai K-

$91 \quad$\begin{tabular}{l|l} 
E-ISSN $2656-4173$ \\
P-ISSN $1907-8455$
\end{tabular} 
ZS sebesar 0,438 dengan taraf signifikansi sebesar 0,991 ( $p>0,05)$. Hal ini menunjukkan bahwa data kecemasan menghadapi pertandingan diperoleh memiliki distribusi normal.

Hasil uji normalitas terdapat pada data kepercayaan diri diperoleh nilai K-ZS sebesar 1,136 dengan taraf signifikansi sebesar 0,151 ( $p>0,05)$. Hal ini menunjukkan bahwa data kepercayaan diri yang diperoleh memiliki distribusi normal.

Hasil uji normalitas terdapat pada data regulasi emosi diperoleh nilai K-ZS sebesar 0,989 dengan taraf signifikansi sebesar $0,282(p>0,05)$. Hal ini menunjukkan bahwa data regulasi emosi yang diperoleh memiliki distribusi normal.

Tabel 1. Hasil Uji Normalitas

One-Sample Kolmogorov-Smirnov Test

\begin{tabular}{|c|c|c|c|c|}
\hline \multicolumn{5}{|c|}{$\begin{array}{l}\text { Kecemasan } \\
\text { Menghadapi } \\
\text { Pertandingan }\end{array}$} \\
\hline$N$ & & 74 & 74 & 74 \\
\hline \multirow[t]{2}{*}{ Normal Parameters ${ }^{\mathrm{a}}$} & Mean & 61.55 & 127.74 & 30.58 \\
\hline & Std. Deviation & 6.859 & 12.166 & 3.793 \\
\hline \multirow{3}{*}{$\begin{array}{l}\text { Most Extreme } \\
\text { Differences }\end{array}$} & Absolute & .051 & .132 & .115 \\
\hline & Positive & .051 & .066 & .115 \\
\hline & Negative & -.046 & -.132 & -.073 \\
\hline \multicolumn{2}{|l|}{ Kolmogorov-Smirnov Z } & .438 & 1.136 & .989 \\
\hline \multicolumn{2}{|l|}{ Asymp. Sig. (2-tailed) } & .991 & .151 & .282 \\
\hline
\end{tabular}

a. Test distribution is Normal.

Pada uji lineritas antara variabel kecemasan menghadapi pertandingan dengan variabel kepercayaan diri diperoleh nilai Flinier sebesar 43,997 dengan taraf signifikansi $p=0,000(p<0,01)$. Hasil ini menunjukkan bahwa antara variabel kecemasan menghadapi pertandingan dengan variabel kepercayaan diri terdapat hubungan yang linier.

Hasil uji linieritas antara variabel kecemasan menghadapi pertandingan dengan variabel regulasi emosi diperoleh nilai $F_{\text {linier }}$ sebesar 15,433 dengan taraf signifikansi $p=0,000(p<0,01)$. Hasil ini menunjukkan bahwa antara variabel kecemasan menghadapi pertandingan dengan variabel regulasi emosi terdapat hubungan yang linier, artinya hubungan antara kedua variabel bebas dan tergantung saling terpenuhi.

Pada uji hipotesis dihasilkan korelasi $R_{y(1,2)}$ sebesar 0,629, $F_{\text {hitung }}$ sebesar 23,269 dengan taraf signifikansi sebesar $0,000(p<0,01)$. Hasil tersebut menunjukkan bahwa terdapat hubungan yang signifikan antara kepercayaan diri dan regulasi emosi dengan kecemasan menghadapi pertandingan.

Tabel 2. Hasil Uji Hipotesis 1 
ANOVA $^{b}$

\begin{tabular}{lllllll}
\hline Model & & Sum of Squares & Df & Mean Square & $F$ & Sig. \\
\hline 1 & Regression & 1359.769 & 2 & 679.884 & 23.269 & $.000^{\text {a }}$ \\
& Residual & 2074.515 & 71 & 29.219 & & \\
& Total & 3434.284 & 73 & & & \\
\hline
\end{tabular}

a. Predictors: (Constant), Regulasi Emosi, Kepercayaan Diri

b. Dependent Variable: Kecemasan Menghadapi Pertandingan

Uji hipotesis yang kedua untuk melihat hubungan antara kepercayaan diri terhadap kecemasan menghadapi pertandingan pada atlet karate di kota Demak. Hasil perhitungan nilai korelasi bivariate $r_{x 1 y}=-0,616$, dengan taraf nilai signifikansi $p=0,000(p<0,01)$, artinya variabel bersifat signifikan. Hasil menunjukkan bahwa ada hubungan signifikan antara kepercayaan diri dan kecemasan menghadapi pertandingan, dengan nilai $r$ negatif yang menunjukkan arah hubungan bersifat negatif.

Tabel 3. Hasil Uji Hipotesis 2

\section{Correlations}

\begin{tabular}{|c|c|c|c|}
\hline & & $\begin{array}{c}\text { Kecemasan Menghadapi } \\
\text { Pertandingan }\end{array}$ & Kepercayaan Diri \\
\hline \multirow{5}{*}{$\begin{array}{l}\text { Kecemasan Menghadapi } \\
\text { Pertandingan }\end{array}$} & Pearson Correlation & 1 & $-.616^{\star \star}$ \\
\hline & Sig. (2-tailed) & & .000 \\
\hline & $\begin{array}{l}\text { Sum of Squares and Cross- } \\
\text { products }\end{array}$ & 3434.284 & -3751.473 \\
\hline & Covariance & 47.045 & -51.390 \\
\hline & $\mathrm{N}$ & 74 & 74 \\
\hline \multirow[t]{5}{*}{ Kepercayaan Diri } & Pearson Correlation & $-.616^{* *}$ & 1 \\
\hline & Sig. (2-tailed) & .000 & \\
\hline & $\begin{array}{l}\text { Sum of Squares and Cross- } \\
\text { products }\end{array}$ & -3751.473 & 10804.122 \\
\hline & Covariance & -51.390 & 148.002 \\
\hline & $\mathrm{N}$ & 74 & 74 \\
\hline
\end{tabular}

**. Correlation is significant at the 0.01 level (2-tailed).

Hasil uji hipotesis kedua tersebut memiliki kemiripan dengan penelitian yang dilakukan oleh Nainggola(2011) tentang kepercayaan diri dan kecemasan sosial. Judul penelitian tersebut tentang hubungan antara kepercayaan diri terhadap kecemasan sosial pada pengguna NAPZA: penelitian di Balai Kasih Sayang Parmadi Siwi. Penelitian dilakukan dengan pemberikan kuesioner pada para penggunga narkoba yang sedang menjalani pemulihan pada 37 orang, terdiri dari 10 orang terapi medis dan 27 orang terapi sosial. Hasil penelitian tersebut menemukan ada hubungan antara kepercayaan diri dengan kecemasan sosial pada pengguna NAPZA di Balai Kasih Sayang Parmadi Siwi.

Pada penelitian Nainggola (2011) mengemukakan dimana dalam mengatasi kecemasan sosial yang dialami subjek. Pihak Balai Kasih Sayang Parmadi Siwi harus menambahkan materi-materi peningkatan kepercayaan diri, ketika akan diadakannya terapi sosial. Hal ini diharapkan agar kecemasan sosialnya 
turun. Melihat penelitian diatas dimana kepercayaan diri sangat diperlukan dalam menghadapi kecemasan sosial. Ini sama dengan penelitian hubungan antara kepercayaan diri terhadap kecemasan menghadapi pertandingan pada atlet karate di kota Demak. Peneliti mengharapkan atlet karate di kota Demak memiliki kepercayaan diri yang tinggi, agar mampu mengatasi kecemasan menghadapi pertandingan.

Setyobroto (2002) dalam penelitiannya memaparkan bahwa sebagai atlet apabila tidak mempunyai kepercayaan diri penuh, maka tidak akan mencapai cita-cita. Kurangnya kepercayaan diri menjadikan terhambatnya atlet dalam mencapai berprestasi tinggi. Atlet yang mengalami kegagalan biasanya akan diliputi perasaan putus asa dan beban untuk menjadi menang. Weinberg dan Gold (2015) menjelaskan bahwa kepercayaan diri memberikan dampak pada atlet, antara lain konsentrasi, emosi, strategi, usaha, momentum dan sasaran.

Hipotesis ketiga untuk mengetahui hubungan antara regulasi emosi dengan kecemasan menghadapi pertandingan pada atlet karate di kota Demak. Hasil perhitungan nilai korelasi bivariate $r_{x 2 y}=-0,420$, dengan taraf nilai signifikansi $p=0,000(p<0,01)$, artinya variabel bersifat signifikan. Hasil menunjukkan bahwa ada hubungan signifikan antara regulasi emosi dan kecemasan menghadapi pertandingan, dengan nilai $r$ negatif yang menunjukkan arah hubungan bersifat negatif.

Tabel 4. Hasil Uji Hipotesis 3

\begin{tabular}{|c|c|c|c|}
\hline \multicolumn{4}{|c|}{ Correlations } \\
\hline & & $\begin{array}{l}\text { Kecemasan } \\
\text { Menghadapi } \\
\text { Pertandingan }\end{array}$ & Regulasi Emosi \\
\hline \multirow{5}{*}{$\begin{array}{l}\text { Kecemasan Menghadapi } \\
\text { Pertandingan }\end{array}$} & Pearson Correlation & 1 & $-.420^{\star *}$ \\
\hline & Sig. (2-tailed) & & .000 \\
\hline & $\begin{array}{l}\text { Sum of Squares and Cross- } \\
\text { products }\end{array}$ & 3434.284 & -797.824 \\
\hline & Covariance & 47.045 & -10.929 \\
\hline & $\mathrm{N}$ & 74 & 74 \\
\hline \multirow[t]{5}{*}{ Regulasi Emosi } & Pearson Correlation & $-.420^{* *}$ & 1 \\
\hline & Sig. (2-tailed) & .000 & \\
\hline & $\begin{array}{l}\text { Sum of Squares and Cross- } \\
\text { products }\end{array}$ & -797.824 & 1050.014 \\
\hline & Covariance & -10.929 & 14.384 \\
\hline & $\mathrm{N}$ & 74 & 74 \\
\hline
\end{tabular}

${ }^{* \star}$. Correlation is significant at the 0.01 level (2-tailed).

Gloud dkk (2002) berpendapat bahwa perkembangan psikologis dapat berpengaruh pada atlet dan institusi, yang termasuk keluarga, komunitas, orang-orang yang mendukung olahraga, diri sendiri, prosesnya olahraga dan lingkungan olahraga tersebut. Perkembangan psikologis yang dirasakan atlet dapat terpengaruh dari lingkungan sekitar sampai pengaruh individu sendiri, sehingga akan berpengaruh pada perkembangan dalam karakter atlet.

Regulasi emosi yang rendah sangat merugikan untuk seorang atlet termasuk pada atlet karate. Sebaliknya berbeda apabila atlet yang memiliki regulasi emosi yang tinggi, akan sangat menguntungkan dalam mengatasi kecemasan menghadapai pertandingan. Permasalahan dalam 
regulasi emosi saat ini tidaklah begitu menjadi masalah besar bagi atlet. Hal ini di dukung dengan latihan rutin, seringnya diadakan uji coba pertandingan dan kesiapan atlet yang sudah matang saat akan menghadapi pertandingan. Kesiapan atlet karate yaitu selain adakan uji coba pertandingan dan penggemblengan mental yang penuh tekanan. Tekanan-tekanan yang diberikan kepada atlet dimaksutkan agar atlet mempunyai mental yang keras dan tangguh.

Hasil penelitian ini memiliki kemiripan dengan penelitian yang dilakukan oleh Sulistyo (2014) yang berjudul hubungan antara regulasi emosi dengan kecemasan menghadapi pertandingan di UKM Universitas Muhammadiyah Surakarta. Hasil penelitiannya yaitu terdapat hubungan negatif yang sangat signifikan antara regulasi emosi dengan kecemasan menghadapi pertandingan. Semakin tinggi regulasi emosi, maka semakin rendah kecemasan menghadapi pertandingan dan begitu juga sebaliknya.

\section{Kesimpulan}

Berdasarkan penelitian, yang telah dilakukan dapat disimpulkan bahwa :

1. Pada hipotesis pertama ada hubungan yang sangat signifikan antara kepercayaan diri dan regulasi emosi terhadap kecemasan menghadapi pertandingan pada atlet karate di kota Demak. Menunjukan hasil diterima.

2. Hipotesis kedua menunjukan hasil yang diterima, yang berarti terdapat hubungan negatif yang sangat signifikan antara kepercayaan diri terhadap kecemasan menghadapi pertandingan pada atlet karate di kota Demak. Semakin tinggi kepercayaan dirinya, maka semakin rendah kecemasan menghadapi pertandingan. Sebaliknya, jika semakin rendah kepercayaan dirinya, maka akan semakin tinggi kecemasan menghadapi pertandingan.

3. Hipotesis ketiga diterima, yang berarti terdapat hubungan negatif yang sangat signifikan antara regulasi emosi terhadap kecemasan menghadapi pertandingan pada atlet karate di Demak. Semakin tinggi regulasi emosinya, maka semakin rendah kecemasan menghadapi pertandingan. Sebaliknya, jika semakin rendah regulasi emosinya, maka akan semakin tinggi kecemasan menghadapi pertandingan.

\section{Saran}

1. Saran bagi para atlet karate

Saran dalam penelitian ini untuk atlet karate di Demak yaitu, agar dapat mempertahankan kepercayaan diri yang tinggi, dengan cara atlet sering ikut bertanding dan sering diadakannya pertemuan antar perguruan yang diayomi Forki. Sedangkan untuk variabel regulasi emosi lebih ditingkatkan lagi dengan cara atlet sering belatih uji coba pertandingan.

2. Saran bagi peneliti selanjutnya

Peneliti yang akan mendatang disarankan untuk melakukan penelitian mengenai faktor-faktor lain dari kecemasan menghadapi pertandingan seperti optimisme, penyebab lingkungan baru, dukungan pelatih dan dukungan sosial. Selain itu penelitian mengenai hubungan antara kepercayaan diri dan regulasi emosi terhadap kecemasan menghadapi pertanding kepada subjek atlet karate yang masih mengalami kecemasan menghadapi pertandingan. Penelitian kedepan untuk mendapatkan hasil yang lebih detail dan variatif dapat menggunakan metodologi kualitatif ini akan menjadikan lebih optimalnya penelitian dalam menggali dan menganalisa kecemasan menghadapi pertandingan pada atlet karate. 
3. Saran bagi pengurus

Pihak pengurus yang berperan sebagai ketua dan pengurus FORKI di Demak sebaiknya lebih memperhatikan para atletnya pada kesiapan mental, dan memberikan dukungan penuh saat akan menghadapi pertandingan agar tidak menjadikan turunya mental bertanding saat akan menjelang pertandingan.

\section{Daftar Pustaka}

Amir, N. (2012). Perngembangan alat ukur kecemasan olahraga. Jurnal Penelitian Dan Evaluasi Pendidikan Vol.16 No.1.

Arikunto, S. (2006). Prosedur penelitian suatu pendekatan praktik. Jakarta: PT. Renika Cipta.

Bandura. (2005). Social cognitive theory. New jersey: Pretice Halls, Inc.

Cashmore, E. (2008). Sport and Exercise Psychology: The Key Concepts Second Edition. New York: Routledge.

Catty, B. J. (1973). Psychology in contemporary sport. London: Prentice Hall.

Gross, J. J. (2007). Emotion regulation.Personality Issues , 497-512.

Gross, J. J., \&Jhon, O. P. (2003). Individual differences in two emotion regulation processes: implications for affect, relationships, and well-being. Journal of Personality and Social Psychology, Vol.85, No.2 , 348-362.

Gunarsa, S. D. (2008). Psikologi olahraga prestasi. Jakarta: BPK Gunung Mulia.

Hapsari, A., \& Primastuti, E. (2014). Kepercayaan diri mahasiswa Papua ditinjau dari dukungan teman sebaya. Psikodimensia Vol.13 No.1, 60-72.

Humas. (2014, June 20). Menko Kesra : prestasi olahraga menjadi tolak ukur kemajuan bangsa dan negara. Retrieved Oktober 6, 2017, from Kementrian Koordinator Bidang Pembangunan Manusia dan Kebudayaan: https://www.kemenkopmk.go.id/artikel/menko-kesra-prestasiolahraga-menjadi-tolok-ukur-kemajuan-bangsa-dan-negara

Komarudin. (2016). Psikologi olahraga. Bandung: PT.Remaja Rosdakarya.

Prihastono, A. (1994). Pembinaan kondisi fisik karate (optimalkan kondisi fisik atlet menuju prestasi puncak). Solo: CV.Aneka.

Rachmawati, L. P., Kartini, S. M., \& Priyatama, A. N. (2013). Hubungan antara kepercayaan diri dengan kecemasan menghadapi pertandingan pada atlet Karate Unit Kegiatan Mahasiswa Institut Karate-do Indonesia Universitas Sebelas Maret (UKM INKAI UNS). Jurnal IImiah Psikologi Candrajiwa , 245-258.

Rahmaiah, S. (2003). Kecemasan bagaimana mengatasi penyebabnya. Jakarta: Pustaka Populer Obor. 
Syahida Alwin Widya Putri dan Agustin Handayani

Santoso, H. D. (2005). Hubungan antara dukungan suporter dengan tingkat kepercayaan diri pada pemain sepak bola.Skripsi. Yogjakarta: Fakultas Psikologi Universitas Islam Indonesia.

Satiadarma, M. P. (2000). Dasar-dasar psikologi olahraga. Jakarta: Pustaka Sinar Harapan.

Singer, R. N. (1993). Ethical issues in clinical services. American Academy Of Psysical Education , 88105.

Sitepu, I. D. (2016). Dampak kecemasan pada atlet bola basket sebelum memulai pertandingan. Jurnal Psikologi Konseling Vol. 8 No.1, Juni , 11-10.

Sujoto, J. B. (1996). Teknik oyama karate. Jakarta: PT.Elex Media Komputindo Kelompok Gramedia.

Sulistyo, E. (2014). Hubungan antara regulasi emosi dengan kecemasan menghadapi pertandingan.Skripsi (pp. 5-18). Surakarta: Universitas Muhammadiyah Surakarta.

Thomas, O., Lane, A., \& Kingston, K. (2011). Defining and contextualizing robust sport confidence. Journal of Applied Sport Psychology, 23 , 189-208. 